\title{
Frequency and Clinical Utility of Olfactory Dysfunction in COVID-19: a Systematic Review and Meta-analysis
}

\author{
Khang Wen Pang ${ }^{1} \cdot$ Jeremy Chee ${ }^{1} \cdot$ Somasundaram Subramaniam ${ }^{2} \cdot$ Chew Lip Ng $^{2}$ \\ Accepted: 8 September 2020 / Published online: 13 October 2020 \\ (C) Springer Science+Business Media, LLC, part of Springer Nature 2020
}

\begin{abstract}
Background Olfactory dysfunction (OD) has been gaining recognition as a symptom of COVID-19, but its clinical utility has not been well defined.

Objectives To quantify the clinical utility of identifying OD in the diagnosis of COVID-19 and determine an estimate of the frequency of OD amongst these patients.

Methods PubMed was searched up to 1 August 2020. Meta-analysis A included studies if they compared the frequency of OD in COVID-19 positive patients (proven by reverse transcription polymerase chain reaction) to COVID-19 negative controls. Metaanalysis B included studies if they described the frequency of OD in COVID-19 positive patients and if OD symptoms were explicitly asked in questionnaires or interviews or if smell tests were performed.

Results The pooled frequency of OD in COVID-19 positive patients (17,401 patients, 60 studies) was 0.56 (0.47-0.64) but differs between detection via smell testing (0.76 [0.51-0.91]) and survey/questionnaire report (0.53 [0.45-0.62]), although not reaching statistical significance $(p=0.089)$. Patients with reported OD were more likely to test positive for COVID-19 (diagnostic odds ratio 11.5 [8.01-16.5], sensitivity 0.48 (0.40 to 0.56$)$, specificity 0.93 (0.90 to 0.96$)$, positive likelihood ratio 6.10 (4.47-8.32) and negative likelihood ratio $0.58(0.52-0.64))$. There was significant heterogeneity amongst studies with possible publication bias.

Conclusion Frequency of OD in COVID-19 differs greatly across studies. Nevertheless, patients with reported OD were significantly more likely to test positive for COVID-19. Patient-reported OD is a highly specific symptom of COVID-19 which should be included as part of the pre-test screening of suspect patients.
\end{abstract}

Keywords Meta-analysis · Severe acute respiratory syndrome $\cdot$ Coronavirus $2 \cdot$ Olfaction disorders $\cdot$ COVID-19

\begin{abstract}
Key Points
Question: What is the clinical utility of olfactory dysfunction (OD) in the diagnosis of COVID-19?

Findings: In this meta-analysis, the pooled frequency of OD in COVID-19 positive patients (17401 patients, 60 studies) was 0.56 (0.47 to 0.64 ). Patients with reported OD were more likely to test positive for COVID19 with a diagnostic odds ratio 11.5 (8.01 to 16.5$)$, sensitivity 0.48 ( 0.40 to 0.56 ), specificity 0.93 ( 0.90 to 0.96 ), positive likelihood ratio 6.05 ( 4.52 to 8.11 ) and negative likelihood ratio 0.60 (0.54 to 0.67 ).

Meaning: Patient-reported OD is a highly specific symptom of COVID19 which should be included as part of the pre-test screening of suspect patients.
\end{abstract}

This article is part of the Topical Collection on Rhinosinusitis

Khang Wen Pang

kwpang1@gmail.com
Department of Otolaryngology-Head and Neck Surgery, National University Hospital, Singapore, Singapore

2 Department of Otolaryngology-Head \& Neck Surgery, Ng Teng Fong General Hospital, Singapore, Singapore 


\section{Introduction}

Olfactory dysfunction has been gaining increasing recognition in the fight against COVID-19 [1,2]. What began as anecdotal reports of patients presenting with anosmia as the sole symptom has evolved into changes in clinical case definitions for suspect cases internationally.

In the context of COVID-19 infections, acute olfactory dysfunction (OD) is defined as decreased or altered sense of smell of a duration of 14 days or less, in the absence of chronic rhinosinusitis, a history of head trauma or neurotoxic medications. OD can be associated with flavour (smell + taste) dysfunction. However, COVID-19 may also affect real taste (sweet, salty, bitter, acidic, umami).

OD is estimated to afflict $3-20 \%$ of the population $[3,4]$. Post-viral anosmia accounts for up to $40 \%$ cases of anosmia or which coronaviruses are thought to account for $10-15 \%$ of these cases [5,6]. As such, it is plausible that COVID-19 may cause OD.

Though the exact pathogenesis is unclear, the high rate of recovery of olfactory function within 1-3 weeks after the onset of OD [7-10] may provide clues on the mechanism and extent of injury to olfactory epithelium and/or neurones. There are two proposed mechanisms by which COVID-19 causes anosmia. Coronaviruses are known to infect olfactory epithelium [11, 12]. Human angiotensin-converting enzyme 2 (ACE-2) receptor, which is a SARS-CoV-2 receptor, is expressed in the olfactory epithelial cells within the olfactory cleft, specifically the sustentacular cells $[13,14]$. Inflammation of the olfactory cleft mucosa can cause conductive OD by reducing airflow and hence odorant presentation to the olfactory cleft [15].

This symptom may hence represent a potential clinical screening tool to facilitate testing of asymptomatic individuals. However, it remains unclear if these findings are causally and uniquely related to COVID-19 infection, or due to increased recognition of OD as a symptom [16]. Amongst patients afflicted with COVID-19, decreased awareness of olfactory dysfunction may be overshadowed by more severe symptoms such as respiratory distress. Furthermore, data in the literature suggests that selfreporting of the sense of smell is specific but not sensitive $[17,18]$. Amongst those with measured olfactory dysfunction, $74.2 \%$ did not recognise it [18]. This is so amongst patients afflicted with COVID-19 as well [19•].

As such, we set out to conduct a systematic review and meta-analysis on OD in COVID-19 to quantify the clinical utility of identifying OD in the diagnosis of COVID-19 and determine an estimate of the frequency of OD amongst these patients. We also aimed to look separately at survey-reported and smell test-reported OD given the reported variance between the two.

\section{Methods}

The Preferred Reporting Items for Systematic reviews and Meta-analyses (PRISMA) Statement [20] was referenced to structure the study. A study protocol was not registered, and no ethics approval was required.

\section{Information Sources and Search Strategy}

Studies were eligible if they were indexed on PubMed. The search was performed on 9 May 2020, and the strategy used was "(anosmia OR smell OR hypos* OR olfact*) AND (COVID* OR SARS-CoV-2 OR 2019-nCoV OR coronavirus)." The search was not limited by publication date and there was no language filter applied. The search was updated on 1 August 2020.

\section{Study Selection and Data Collection}

Screening of titles and abstracts was performed by 2 independent researchers to determine if the studies met the inclusion criteria. If abstracts were not available, the full text was retrieved and analysed. Any disagreements between the 2 researchers were resolved by discussion and by consulting a third, senior researcher. Data extracted from eligible studies included the author, year of publication, study design, country of origin, OD testing method, COVID-19 testing method and number of cases reporting OD amongst COVID-19 positive and negative patients. Data was entered into Excel sheets independently by the 2 researchers and then compared. Methodological quality was rated independently by two reviewers using the risk of bias tool for prevalence studies by Hoy et al. [21].

\section{Inclusion and Exclusion Criteria}

To quantify the clinical utility of identifying OD in the diagnosis of COVID-19, we compared the frequency of OD in patients stratified by COVID-19 test results using the reverse transcription polymerase chain reaction (RTPCR). This was performed in Meta-analysis A. Studies were included if they compared the frequency of smell disturbance in COVID-19 positive patients (proven by RT-PCR) to COVID-19 negative controls in casecontrol studies. Appropriate controls were defined as patients who were suspected of having COVID-19 infection or fulfilled local guidelines for COVID-19 testing but were COVID-19 negative on RT-PCR testing. The data items were the number of COVID-19 positive and negative patients with OD and total number of patients tested. Principal summary measures were pooled 
sensitivity, specificity, positive likelihood ratio (LR), negative LR and diagnostic odd ratios (DOR).

To investigate the estimated frequency of OD amongst COVID-19 patients, meta-analysis B included studies if they described the frequency of OD in COVID-19 positive patients and if smell tests were performed or if OD symptoms were explicitly asked in questionnaires or interviews. The latter criterion was chosen as OD symptoms were not routinely asked in early studies, which might explain the low frequency of OD reported in China. The data items were the number of COVID-19 positive patients with OD. The principal summary measure was the frequency of OD. Subgroup analyses was performed to investigate if the frequency differed between survey/questionnairereported OD and smell test-reported OD.

\section{Statistical Analysis}

R Studio version 1.2.5042 [22] and R version 4.0.0 [23] were used for all statistical analyses. The packages meta [24], mada [25] and dmetar [26] were used in the analyses. All data are presented as effect estimates with $95 \%$ confidence intervals in parenthesis. Heterogeneity amongst studies was tested using the Cochran's $Q$ test and $I^{2}$. A random effects model was used if $I^{2}>50 \%$. Forest plots were generated to summarise the results. Funnel plots and Egger tests were used to detect any publication bias.

\section{Results}

\section{Meta-analysis A: the Clinical Significance OD in the Diagnosis of COVID-19}

A total of 498 studies were retrieved from PubMed. A total of 422 articles were excluded based on their titles and abstracts, and 57 of the remaining 76 articles were excluded for reasons as described in Fig. 1. The remaining 19 articles were included in the meta-analysis.

\section{Study Characteristics}

A total of 1861 COVID-19 positive patients and 15,556 COVID-19 negative patients were included across the 19 studies as seen in Table 1. The patients were from Canada, France, Germany, Hungary, Italy, Netherlands, Singapore, Spain, Turkey and the USA. All studies utilised RT-PCT as the COVID-19 diagnostic testing method. All studies described survey/questionnaire-reported OD.

\section{Clinical Utility of Identifying OD in the Diagnosis of COVID-19}

With reference to Fig. 2, patients with OD were more likely to test positive for COVID-19 (DOR 11.5 (8.01 to 16.5), positive LR 6.10 (4.47 to 8.32) and negative LR 0.58 (0.52 to 0.64$)$ ). The pooled sensitivity was 0.48 ( 0.40 to 0.56 ), and the pooled specificity was 0.93 (0.90 to 0.96 ) in using OD to predict
Fig. 1 Flow diagram for metaanalysis A showing the clinical significance of OD in the diagnosis of COVID-19. ${ }^{\text {a}}$ Fifty-seven full-text articles were excluded: 49 did not include controls, 4 utilised inappropriate controls who were not swabbed for COVID-19 (3 studies used healthy asymptomatic individuals as controls and 1 study used historical influenza patients as controls), 2 utilised self-reported COVID testing results, 1 added in OD symptoms to their data collection sheet midway through the study and 1 did not explicitly ask for OD symptoms

\section{氖}

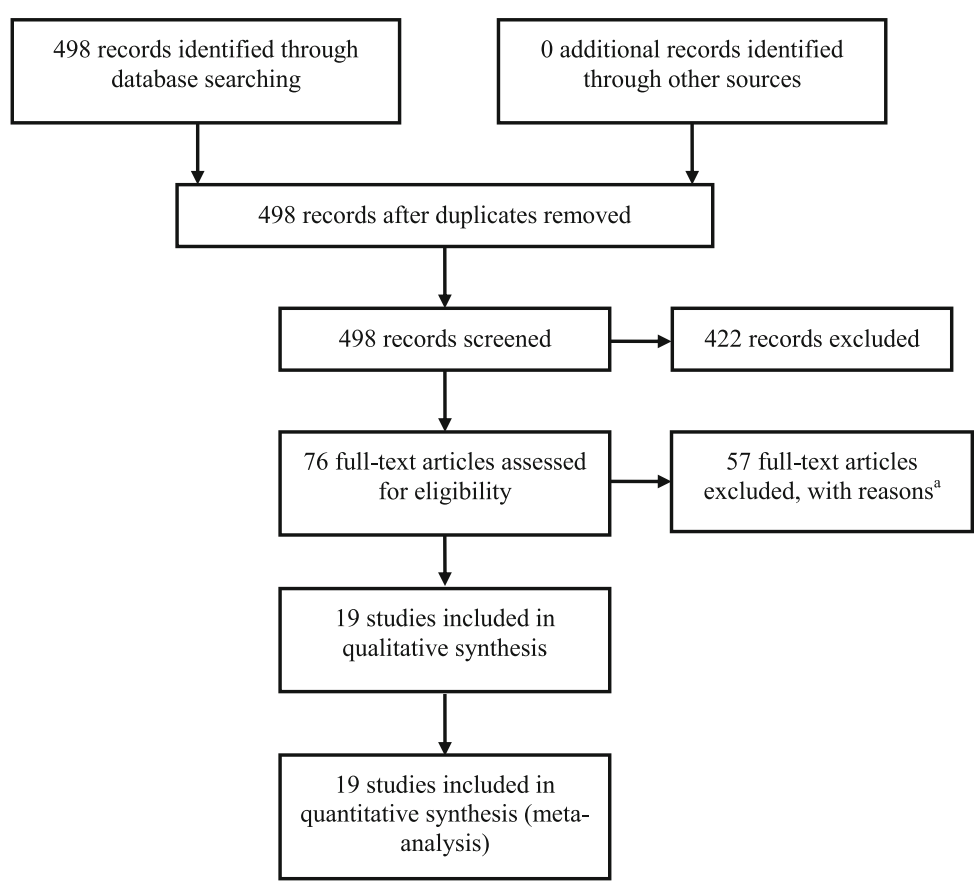


Table 1 Characteristics of full-text articles assessed for eligibility

\begin{tabular}{|c|c|c|c|c|c|c|c|c|}
\hline \multirow[t]{2}{*}{ Author } & \multirow[t]{2}{*}{ Country } & \multirow[t]{2}{*}{ Study design } & \multicolumn{2}{|c|}{$\begin{array}{l}\text { COVID } \\
\text { positive }\end{array}$} & \multicolumn{2}{|c|}{$\begin{array}{l}\text { COVID } \\
\text { negative }\end{array}$} & \multirow[t]{2}{*}{ OD testing method } & \multirow{2}{*}{$\begin{array}{l}\text { COVID } \\
\text { testing } \\
\text { method }\end{array}$} \\
\hline & & & OD & Total & OD & Total & & \\
\hline \multicolumn{9}{|c|}{ Questionnaire-reported OD studies included in both meta-analyses A and B } \\
\hline Bénézit, 2020 [27] & France & Case-control study & 31 & 68 & 19 & 189 & Online questionnaire & RT-PCR \\
\hline Brandstetter, 2020 [28] & Germany & Case-control study & 16 & 31 & 4 & 170 & Structured interview & RT-PCR \\
\hline Carignan, 2020 [29] & Canada & Case-control study & 69 & 134 & 6 & 134 & Questionnaire by phone & RT-PCR \\
\hline Chua, 2020 [30] & Singapore & Case-control study & 7 & 31 & 22 & 686 & $\begin{array}{l}\text { Prospective verbal } \\
\text { interview }\end{array}$ & RT-PCR \\
\hline Dawson, 2020 [31] & USA & Case-control study & 18 & 42 & 1 & 48 & Questionnaire & RT-PCR \\
\hline Greffe, 2020 [32] & France & Case-control study & 75 & 195 & 12 & 324 & $\begin{array}{l}\text { Questionnaire } \\
\text { (prospective) }\end{array}$ & RT-PCR \\
\hline Haehner, 2020 [33] & Germany & $\begin{array}{l}\text { Cross-sectional controlled } \\
\text { cohort survey }\end{array}$ & 22 & 34 & 47 & 466 & Questionnaire & RT-PCR \\
\hline $\begin{array}{l}\text { Izquierdo-Domínguez, } \\
2020 \text { [34] }\end{array}$ & Spain & Case-control study & 454 & 846 & 43 & 143 & Questionnaire & RT-PCR \\
\hline Lee DJ, 2020 [35] & Canada & Cross-sectional survey & 23 & 56 & 3 & 71 & Online questionnaire & RT-PCR \\
\hline Magnavita, 2020 [36] & Italy & Case-control study & 35 & 82 & 1 & 152 & Questionnaire (recall) & RT-PCR \\
\hline Martin-Sanz, 2020 [37] & Spain & Case-control study & 138 & 215 & 30 & 140 & Questionnaire (recall) & RT-PCR \\
\hline Merkely, 2020 [38] & Hungary & Case-control Study & 12 & 70 & 265 & 10,404 & $\begin{array}{l}\text { Questionnaire } \\
\text { (prospective) }\end{array}$ & RT-PCR \\
\hline Sayin, 2020 [39] & Turkey & Case-control study & 52 & 64 & 15 & 64 & Online questionnaire & RT-PCR \\
\hline Tostmann, 2020 [40] & Netherlands & Cross-sectional survey & 37 & 79 & 7 & 190 & Online questionnaire & RT-PCR \\
\hline Tudrej, 2020 [41] & France & Cross-sectional survey & 82 & 198 & 74 & 618 & Questionnaire & RT-PCR \\
\hline Wee, 2020 [42] & Singapore & Case series & 35 & 154 & 9 & 716 & $\begin{array}{l}\text { Case notes review } \\
\quad(\text { explicitly asked) }\end{array}$ & RT-PCR \\
\hline Yan, 2020a [8] & USA & Cross-sectional survey & 40 & 59 & 33 & 203 & Online questionnaire & RT-PCR \\
\hline Zayet, 2020a [43] & France & $\begin{array}{l}\text { Case-control study, influenza } \\
\text { positive controls }\end{array}$ & 37 & 70 & 9 & 54 & $\begin{array}{l}\text { Standardised } \\
\text { questionnaire } \\
\text { then case notes review }\end{array}$ & RT-PCR \\
\hline Zayet, 2020b [44] & France & Case-control study & 60 & 95 & 18 & 122 & $\begin{array}{l}\text { Standardised questionnaire } \\
\text { then case notes review }\end{array}$ & RT-PCR \\
\hline \multicolumn{9}{|c|}{ Questionnaire-reported OD studies included only in meta-analysis B } \\
\hline Altin, 2020 [45] & Turkey & $\begin{array}{l}\text { Case-control study, } \\
\text { asymptomatic controls not } \\
\text { swabbed }\end{array}$ & 50 & 81 & 0 & 40 & $\begin{array}{l}\text { Questionnaire } \\
\text { (prospective) }\end{array}$ & RT-PCR \\
\hline Barillari, 2020 [46] & Italy & Cross-sectional Survey & 118 & 179 & NA & NA & Questionnaire (recall) & RT-PCR \\
\hline $\begin{array}{l}\text { Beltrán-Corbellini, } \\
2020[47]\end{array}$ & Spain & $\begin{array}{l}\text { Case-control study, historical } \\
\text { influenza positive controls }\end{array}$ & 25 & 79 & 4 & 40 & Questionnaire & RT-PCR \\
\hline Biadsee, 2020 [48] & Israel & Case series & 86 & 128 & NA & NA & Online questionnaire & RT-PCR \\
\hline Chary, 2020 [49] & France & Case series & 106 & 115 & NA & NA & $\begin{array}{l}\text { DyNaCHRON } \\
\text { questionnaire }\end{array}$ & RT-PCR \\
\hline $\begin{array}{l}\text { Chiesa-Estomba, } 2020 \\
\text { [50] }\end{array}$ & $\begin{array}{l}\text { Spanish, Uruguay, } \\
\text { Venezuela, } \\
\text { Argentina }\end{array}$ & Case series & 444 & 542 & NA & NA & $\begin{array}{l}\text { Short version of } \\
\text { Questionnaire } \\
\text { of Olfactory } \\
\text { Disorders-Negative } \\
\text { Statements }\end{array}$ & RT-PCR \\
\hline Chung, 2020 [51] & Hong Kong & $\begin{array}{l}\text { Case-control study, } \\
\text { asymptomatic controls not } \\
\text { swabbed }\end{array}$ & 12 & 18 & 0 & 18 & Questionnaire & RT-PCR \\
\hline Dell'Era, 2020 [52] & Italy & Cross-sectional survey & 237 & 355 & NA & NA & Questionnaire & RT-PCR \\
\hline Foster, 2020 [53] & USA & Case series & 198 & 949 & NA & NA & Questionnaire & RT-PCR ${ }^{\&}$ \\
\hline Freni, 2020 [54] & Italy & Case Series & 46 & 50 & NA & NA & Questionnaire (recall) & RT-PCR \\
\hline Giacomelli, 2020 [55] & Italy & Cross-sectional survey & 14 & 59 & NA & NA & Questionnaire interview & RT-PCR ${ }^{\&}$ \\
\hline Gómez-Iglesias, 2020 [56] & Spain & Cross-sectional survey & 894 & 909 & NA & NA & Online questionnaire (recall) & RT-PCR \\
\hline
\end{tabular}


Table 1 (continued)

\begin{tabular}{|c|c|c|c|c|c|c|c|c|}
\hline \multirow[t]{2}{*}{ Author } & \multirow[t]{2}{*}{ Country } & \multirow[t]{2}{*}{ Study design } & \multicolumn{2}{|c|}{$\begin{array}{l}\text { COVID } \\
\text { positive }\end{array}$} & \multicolumn{2}{|c|}{$\begin{array}{l}\text { COVID } \\
\text { negative }\end{array}$} & \multirow[t]{2}{*}{ OD testing method } & \multirow{2}{*}{$\begin{array}{l}\text { COVID } \\
\text { testing } \\
\text { method }\end{array}$} \\
\hline & & & OD & Total & $\mathrm{OD}$ & Total & & \\
\hline Jalessi, 2020 [57] & Iran & $\begin{array}{l}\text { Cross-sectional Survey } \\
\text { (random sample) }\end{array}$ & 22 & 92 & NA & NA & Questionnaire (recall) & RT-PCR \\
\hline Karadas, 2020 [58] & Turkey & Cross-sectional survey & 18 & 239 & NA & NA & $\begin{array}{l}\text { Questionnaire } \\
\text { (prospective) }\end{array}$ & RT-PCR \\
\hline Kim, 2020 [59] & South Korea & Cross-sectional survey & 68 & 213 & NA & NA & Questionnaire & RT-PCR \\
\hline $\begin{array}{l}\text { Klopfenstein, } 2020 \\
{[60]}\end{array}$ & France & Case series & 54 & 114 & NA & NA & Case notes review & RT-PCR \\
\hline Lechien, 2020e [61] & $\begin{array}{l}\text { Belgium, France, } \\
\text { Spain, Italy, } \\
\text { Switzerland }\end{array}$ & Cross-sectional survey & 1754 & 2013 & NA & NA & Questionnaire (online) & RT-PCR \\
\hline Lee $Y, 2020[10]$ & South Korea & Cross-sectional survey & 389 & 3191 & NA & NA & Questionnaire by phone & RT-PCR \\
\hline Levinson, 2020 [62] & Israel & Case series & 15 & 42 & NA & NA & Questionnaire & RT-PCR \\
\hline Liang, 2020 [63] & China & Cross-sectional Survey & 34 & 86 & NA & NA & Questionnaire(recall) & RT-PCR \\
\hline Liguori, 2020 [64] & Italy & Case series & 40 & 103 & NA & NA & Standardised interview & RT-PCR \\
\hline Luers, 2020 [65] & Germany & Cross-sectional survey & 53 & 72 & NA & NA & Questionnaire & RT-PCR \\
\hline Meini, 2020 [66] & Italy & Case series & 29 & 100 & NA & NA & Questionnaire by phone & RT-PCR \\
\hline Mercante, 2020 [67] & Italy & Case series & 85 & 204 & NA & NA & Italian SNOT-22 & RT-PCR \\
\hline Noh, 2020 [68] & South Korea & Case series & 52 & 199 & NA & NA & Interview & RT-PCR \\
\hline Otte, 2020 [69] & Germany & Case series & 47 & 50 & NA & NA & Patient reported & RT-PCR \\
\hline Paderno, 2020a [70] & Italy & Cross-sectional survey & 283 & 508 & NA & NA & Questionnaire (recall) & RT-PCR \\
\hline Patel, 2020 [71] & UK & Case series & 80 & 141 & NA & NA & Questionnaire by phone & RT-PCR \\
\hline Qiu, 2020 [72] & $\begin{array}{c}\text { China, France, } \\
\text { Germany }\end{array}$ & Case series & 154 & 394 & NA & NA & $\begin{array}{l}\text { Questionnaire of } \\
\text { olfactory disorders }\end{array}$ & RT-PCR \\
\hline Renaud, 2020 [73] & France & Case series & 96 & 97 & NA & NA & Questionnaire & RT-PCR \\
\hline Sierpiński, 2020 [74] & Poland & Cross-sectional survey & 956 & 1942 & NA & NA & Questionnaire & RT-PCR \\
\hline Speth, 2020 [75] & Switzerland & Cross-sectional survey & 63 & 103 & NA & NA & Questionnaire by phone & RT-PCR \\
\hline Spinato, $2020[76]$ & Italy & Cross-sectional survey & 130 & 202 & NA & NA & $\begin{array}{l}\text { Questionnaire by phone, } \\
\text { SNOT } 22\end{array}$ & RT-PCR \\
\hline Villarreal, 2020 [77] & Spain & Case series & 157 & 230 & NA & NA & Questionnaire & RT-PCR \\
\hline Wi, $2020[78]$ & Korea & Cross-sectional Survey & 15 & 102 & NA & NA & Questionnaire (prospective) & RT-PCR \\
\hline Yan, 2020b [15] & USA & Case series & 75 & 128 & NA & NA & $\begin{array}{l}\text { Case notes review and } \\
\text { phone/e-mail interview }\end{array}$ & RT-PCR \\
\hline \multicolumn{9}{|c|}{ Smell test-reported OD studies included only in meta-analysis B } \\
\hline Hornuss, 2020 [79] & Germany & $\begin{array}{l}\text { Case-control study, } \\
\text { asymptomatic controls not } \\
\text { swabbed }\end{array}$ & 38 & 45 & 12 & 45 & Sniffin’ Sticks & RT-PCR \\
\hline Lechien, 2020d [80] & Belgium & Case series & 53 & 86 & NA & NA & Sniffin' Sticks & RT-PCR \\
\hline Moein, 2020 [19•] & Iran & Cross-sectional survey & 59 & 60 & NA & NA & UPSIT & RT-PCR \\
\hline Petrocelli, 2020 [81] & Italy & Case Series & 190 & 300 & NA & NA & Ethyl alcohol & RT-PCR \\
\hline Vaira, 2020a [9] & Italy & Cross-sectional survey & 60 & 72 & NA & NA & CCCRC test & RT-PCR \\
\hline Vaira, 2020b [82] & Italy & Cross-sectional survey & 104 & 345 & NA & NA & $\begin{array}{l}\text { CCCRC and ethyl } \\
\text { alcohol tests }\end{array}$ & RT-PCR \\
\hline \multicolumn{9}{|c|}{ Excluded studies after full text review } \\
\hline Abalo-Lojo, 2020 [83] & Spain & Case series & 77 & 131 & NA & NA & $\begin{array}{l}\text { Patient reported } \\
\text { Unclear if explicitly } \\
\text { asked }\end{array}$ & RT-PCR \\
\hline Adorni, $2020[84]^{\%}$ & Italy & Cross-sectional Survey & 507 & 856 & 291 & 3536 & Questionnaire (recall) & RT-PCR \\
\hline Aggarwal, 2020 [85] & USA & Case series & 3 & 16 & NA & NA & $\begin{array}{l}\text { Case notes review } \\
\text { Unclear if explicitly } \\
\text { asked }\end{array}$ & RT-PCR \\
\hline
\end{tabular}


Table 1 (continued)

\begin{tabular}{|c|c|c|c|c|c|c|c|c|}
\hline \multirow[t]{2}{*}{ Author } & \multirow[t]{2}{*}{ Country } & \multirow[t]{2}{*}{ Study design } & \multicolumn{2}{|c|}{$\begin{array}{l}\text { COVID } \\
\text { positive }\end{array}$} & \multicolumn{2}{|c|}{$\begin{array}{l}\text { COVID } \\
\text { negative }\end{array}$} & \multirow[t]{2}{*}{ OD testing method } & \multirow{2}{*}{$\begin{array}{l}\text { COVID } \\
\text { testing } \\
\text { method }\end{array}$} \\
\hline & & & OD & Total & $\mathrm{OD}$ & Total & & \\
\hline Gelardi, 2020 [86] & Italy & Case series & 42 & 72 & NA & NA & Unclear & RT-PCR \\
\hline Lechien, 2020a $[87]^{\wedge}$ & $\begin{array}{l}19 \text { European } \\
\text { Hospitals }\end{array}$ & Cross-sectional Survey & 583 & 702 & NA & NA & Questionnaire (recall) & RT-PCR \\
\hline 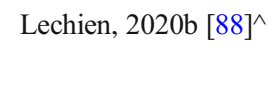 & $\begin{array}{l}\text { Belgium, France, } \\
\text { Spain, Italy, } \\
\text { Switzerland }\end{array}$ & Cross-sectional survey & 997 & 1420 & NA & NA & $\begin{array}{l}\text { Questionnaire (interview, } \\
\text { phone, online) }\end{array}$ & RT-PCR \\
\hline Lechien, 2020c $[7]^{\wedge}$ & $\begin{array}{l}\text { Belgium, France, } \\
\text { Spain, Italy }\end{array}$ & Case series & 357 & 417 & NA & NA & Questionnaire (online) & RT-PCR \\
\hline Lehrich, 2020 [89] & Italy & Case series & 42 & 72 & NA & NA & Not stated & RT-PCR \\
\hline Mao, 2020 [90] & China & Case series & 11 & 214 & NA & NA & $\begin{array}{l}\text { Case notes review } \\
\text { Unclear if explicitly } \\
\text { asked }\end{array}$ & RT-PCR \\
\hline Menni, $2020[16]^{\%}$ & UK & Cross-sectional survey & 342 & 579 & 202 & 1123 & $\begin{array}{r}\text { Online COVID RADAR } \\
\text { Symptom Tracker app }\end{array}$ & RT-PCR \\
\hline $\begin{array}{l}\text { Paderno, 2020b } \\
{[91 \bullet \bullet]^{@}}\end{array}$ & Italy & Cross-sectional survey & 125 & 151 & NA & NA & Questionnaire (recall) & RT-PCR \\
\hline Peyrony, 2020[92] & France & Case-control study & 31 & 225 & 3 & 166 & $\begin{array}{l}\text { Questionnaire (OD only } \\
\text { added in midway) }\end{array}$ & RT-PCR \\
\hline $\begin{array}{l}\text { Romero-Sánchez, } \\
2020 \text { [93] }\end{array}$ & Spain & Case series & 41 & 841 & NA & NA & $\begin{array}{l}\text { Case notes review (not } \\
\text { explicitly asked) }\end{array}$ & RT-PCR \\
\hline Trigo, 2020 [94] & Spain & Case series & 146 & 576 & NA & NA & $\begin{array}{l}\text { Case notes review (not } \\
\text { explicitly asked) }\end{array}$ & RT-PCR \\
\hline Trubiano, 2020 [95] & Australia & Case-control study & 7 & 28 & 62 & 1208 & $\begin{array}{l}\text { Case notes review (not } \\
\text { explicitly asked) }\end{array}$ & RT-PCR \\
\hline
\end{tabular}

OD olfactory dysfunction, UPSIT University of Pennsylvania Smell Identification Test, SNOT22 Sino-nasal Outcome Test, CCCRC test Connecticut Chemosensory Clinical Research Center orthonasal olfaction test, $N A$ not available

\& Personal communication with study authors confirmed RT-PCR as diagnostic testing method

Yan, 2020a [8] was not included in meta-analysis B of prevalence of OD as data likely overlaps with the other paper published by Yan [15]

${ }^{\wedge}$ Excluded due to overlapping dataset. The largest series by Lechien [61] was included in the analyses

${ }^{\%}$ Excluded as COVID-19 testing and result was self-reported by patients and not verified

${ }^{\circledR}$ Excluded as it is a follow-up study of the same dataset

COVID-19 infection. There was significant heterogeneity amongst the 6 studies $\left(I^{2}=76.4 \%, p<0.0001\right)$. The Funnel plot is shown in Fig. 5a. Egger's test suggested the presence of publication bias $(p<0.001)$.

\section{Meta-analysis B: Estimating the Frequency of OD Amongst COVID-19 Patients}

A total of 498 studies were retrieved from PubMed. A total of 422 articles were excluded based on their titles and abstracts, and 16 of the remaining 76 articles were excluded for reasons as described in Fig. 3. The remaining 60 articles were included in the meta-analysis.

\section{Study Characteristics}

A total of 17,401 COVID-19 positive patients across 60 studies were included in Meta-analysis B, of which 8606 reported OD. The patients were from all major continents. All utilised RT-PCT as the COVID-19 diagnostic testing method. All used questionnaire-based, symptom-based reporting of OD except for 6 studies (2 used Sniffin' Sticks, 1 used UPSIT, 1 used the Connecticut Chemosensory Clinical Research Test (CCCRT), 1 used ethyl alcohol and 1 used a combination of CCCRT and ethyl alcohol).

\section{Estimating the Frequency of OD Amongst COVID-19 Patients}

With reference to Fig. 4, the overall pooled frequency of OD amongst COVID-19 patients was 0.56 (0.47 to 0.64 ). There was significant heterogeneity amongst the 60 studies $\left(I^{2}=\right.$ $98.8 \%, p<0.001)$. Funnel plot is shown in Fig. 5b. Egger's test did not suggest the presence of publication bias $(p=0.204)$. 
Fig. 2 Meta-analysis A showing the clinical significance OD in the diagnosis of COVID-19. a

Diagnostic odds ratio. b Pooled sensitivity. c Pooled specificity of OD in predicting COVID-19 infection a

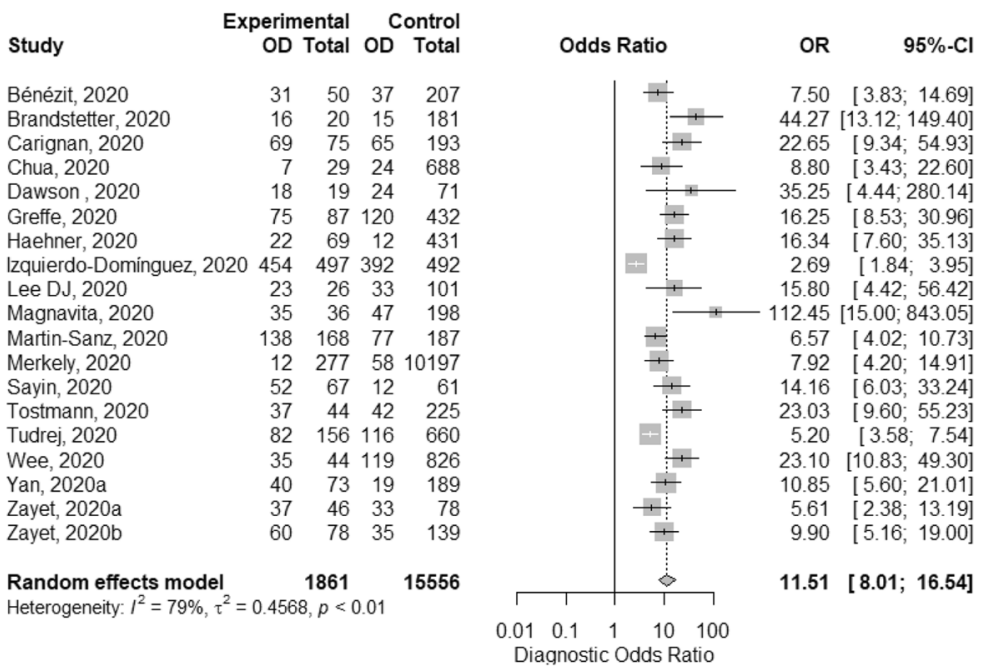

b
Study

Bénézit, 2020

Brandstetter, 2020

Carignan, 2020

Chua, 2020

Dawson, 2020

Greffe, 2020

Haehner, 2020

Izquierdo-Dominguez, 2020

Lee DJ, 2020

Magnavita, 2020

Martin-Sanz, 2020

Merkely, 2020

Sayin, 2020

Tostmann, 2020

Tudrej, 2020

Wee, 2020

Yan, 2020a

Zayet, 2020a

Zayet, 2020b

Random effects model

Heterogeneity: $I^{2}=92 \%, \tau^{2}=0.4211, p<0.01$

Olfactory Dysfunction Total

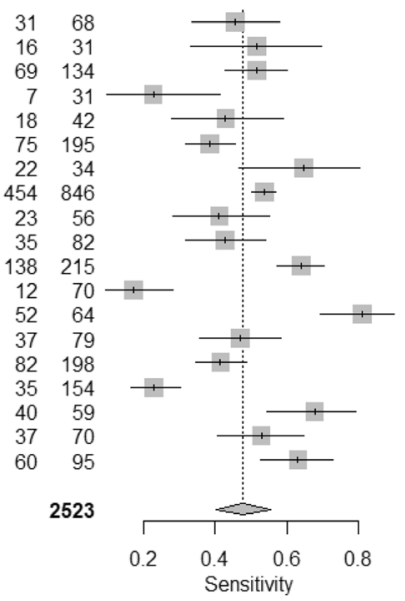

Proportion $\quad 95 \%-\mathrm{Cl}$

$0.46[0.33 ; 0.58]$

$0.52[0.33 ; 0.70]$

$0.51[0.43 ; 0.60]$

$0.23[0.10 ; 0.41]$

$0.43[0.28 ; 0.59]$

$0.38[0.32 ; 0.46]$

$0.65[0.46,0.80]$

$0.54[0.50 ; 0.57]$

$0.41[0.28 ; 0.55]$

$0.43[0.32 ; 0.54$

$0.64[0.57 ; 0.71]$

$0.17[0.09 ; 0.28]$

$0.81[0.70 ; 0.90]$

$0.47[0.36 ; 0.58]$

$0.41[0.34 ; 0.49]$

$0.23[0.16 ; 0.30]$

$0.68[0.54 ; 0.79$

$0.53[0.41 ; 0.65]$

$0.63[0.53 ; 0.73]$

$0.48[0.40 ; 0.56]$ c
Study

Bénézit, 2020

Brandstetter, 2020

Carignan, 2020

Chua, 2020

Dawson, 2020

Greffe, 2020

Haehner, 2020

zquierdo-Dominguez, 2020

Lee DJ, 2020

Magnavita, 2020

Martin-Sanz, 2020

Merkely, 2020

Sayin, 2020

Tostmann, 2020

Tudrej, 2020

Wee, 2020

Yan, 2020a

Zayet, 2020a

Zayet, 2020b
Random effects mode

Heterogeneity: $I^{2}=96 \%, \tau^{2}=1.1211, p<0.01$
Olfactory Dysfunction Total

$\begin{array}{ll}170 & 18 \\ 166 & 170 \\ 128 & 134\end{array}$

$\begin{array}{ll}128 & 134 \\ 664 & 686\end{array}$

$\begin{array}{rr}664 & 686 \\ 47 & 48\end{array}$

$312 \quad 324$

41946

$100 \quad 143$

68

$110 \quad 140$

1013910404

1013910404

183190

$544 \quad 618$

$707 \quad 716$

$\begin{array}{rr}170 & 203 \\ 45 & 54\end{array}$

104

14894
0.650 .70 .750 .80 .850 .90 .95 Specificity
Proportion $\quad 95 \%-\mathrm{Cl}$

$0.90 \quad[0.85 ; 0.94$

$0.98[0.94 ; 0.99]$

$0.96[0.91 ; 0.98]$

$0.97[0.95 ; 0.98]$

$0.98[0.89 ; 1.00]$

$0.96[0.94 ; 0.98]$

$0.90[0.87 ; 0.92]$

$0.70[0.62 ; 0.77$

$0.96[0.88 ; 0.99]$

$0.99[0.96 ; 1.00]$

$0.79[0.71 ; 0.85]$

$0.97[0.97 ; 0.98]$

$0.77[0.64 ; 0.86]$

$0.96[0.93 ; 0.99]$

$0.88[0.85 ; 0.90]$

$0.99[0.98 ; 0.99]$

$0.84[0.78 ; 0.89]$

$0.83[0.71 ; 0.92]$

$0.85[0.78 ; 0.91]$

$0.93[0.90 ; 0.96]$ 
Fig. 3 Flow diagram for metaanalysis B estimating the frequency of OD amongst COVID19 patients. 'Sixteen full-text articles were excluded: 9 did not specify if OD symptoms were explicitly asked, 5 likely used overlapping data and 2 utilised self-reported COVID testing results

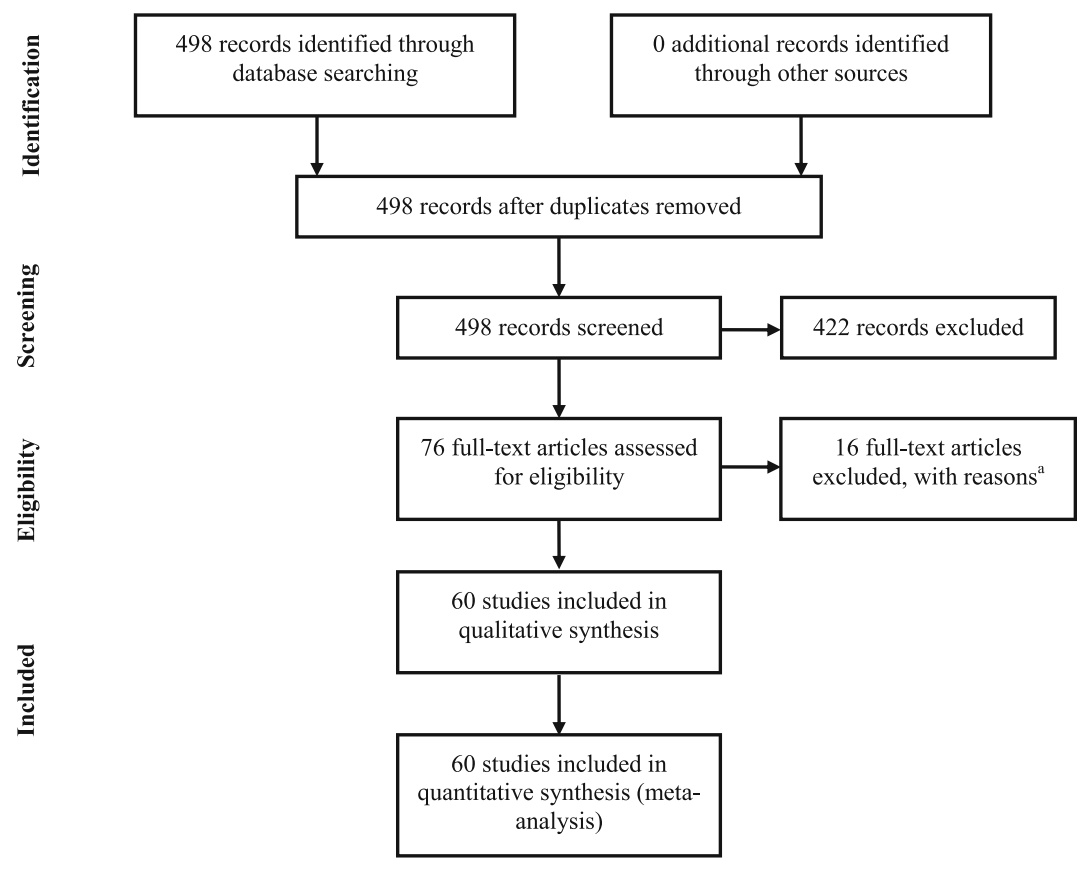

In subgroup analysis in Fig. 4, the frequency of smell test detected OD amongst COVID-19 patients differs between detection via smell testing $(0.76$ [0.51-0.91]) vs survey/ questionnaire report (0.53 [0.45-0.62]), although not reaching statistical significance $(p=0.089)$.

\section{Risk of Bias}

Table 2 summarises the risk of bias of all studies included in both meta-analyses A and B. Overall, the studies were of moderate to high risk of bias due to the lack of smell testing except for 6 studies, the presence of non-response bias using the questionnaire methodology or the inclusion of only particular groups of patients (e.g. only hospitalised patients, or only outpatients, or only those with mild-moderate disease).

\section{Discussion}

The pooled frequency of OD in COVID-19 positive patients $(17,401$ patients, 60 studies) was 0.56 but differed between detection via validated smell testing (0.76) vs survey/questionnaire reports $(0.53)$. This inconsistency of olfactory dysfunction between survey/questionnaire reports and validated smell tests has also been recognised in the literature [17, 18]. Moein et al. [19•] reported that $29 \%$ of their patients reported self-reported OD. However, validated smell tests on this same group of patients showed $58 \%$ to have anosmia or severe microsmia, with only $2 \%$ with normal olfactory function. Similarly, Vaira [9] reported $28.3 \%$ patients having s OD, while
$98 \%$ had OD on validated smell tests. A significant number of patients with olfactory dysfunction do not report symptoms. Even within the realm of administered smell tests, cultural differences may result in inaccurate identification of smell dysfunction [96]. This might suggest that at least some of the variation in frequency rates of OD in COVID-19 may be attributed to differences in data collection methods.

Notwithstanding this, patient-reported OD as a symptom was highly specific $(93 \%)$ but not sensitive $(48 \%)$, for COVID-19 infection. The results of this metaanalysis further suggest that patients with reported OD were more likely to test positive for COVID-19 (diagnostic OR 11.5), with positive (6.10) and negative (0.58) LR. The presence of patient-reported OD can hence be used as an additional screening question to triage patients in determining the need for COVID-19 testing regardless of the presence of other concomitant upper respiratory symptoms. Whether smell test detected OD may serve as a more accurate screening tool remains to be investigated.

It is increasingly recognised that the COVID-19 infection can manifest as mild, moderate, severe or critical illness [97]. Yan et al. [15] reported that patients with OD may be associated with a milder clinical course. Izquierdo-Domínguez also reported that patients with more severe OD were less likely to be hospitalised and had a lower level of C-reactive protein [34]. However, patients who were intubated or deceased at the time of data collection could not be included in their study. If this were indeed true, the presence of OD might assist in 
Fig. 4 Meta-analysis B estimating the frequency of $\mathrm{OD}$ amongst COVID-19 patients.

Pooled prevalence of olfactory dysfunction (OD) amongst

COVID-19 patients with subgroup analysis by OD testing method

Study

Olfactory Dysfunction Total

OD Reported: Survey/Questionnaire Altin, 2020

Barillari, 2020

Beltrán-Corbellini, 2020

Bénézit, 2020

Biadsee, 2020

Brandstetter, 2020

Carignan, 2020

Chary, 2020

Chiesa-Estomba, 2020

Chua, 2020

Chung, 2020

Dawson, 2020

Dell'Era, 2020

Foster, 2020

Freni, 2020

Giacomelli, 2020

Gómez-Iglesias, 2020

Greffe, 2020

Haehner, 2020

Izquierdo-Dominguez, 2020

Jalessi, 2020

Karadas, 2020

Kim, 2020

Klopfenstein, 2020

Lechien, $2020 \mathrm{e}$

Lee DJ, 2020

Lee $Y, 2020$

Levinson, 2020

Liang, 2020

Liguori, 2020

Luers, 2020

Magnavita, 2020

Martin-Sanz, 2020

Meini, 2020

Mercante, 2020

Merkely, 2020

Noh, 2020

Otte, 2020

Paderno, 2020a

Patel, 2020

Qiu, 2020

Renaud, 2020

Sayin, 2020

Sierpinski, 2020

Speth, 2020

Spinato, 2020

Tostmann, 2020

Tudrej, 2020

Villarreal, 2020

Wee, 2020

Wi, 2020

Yan, 2020b

Zayet, 2020a

Zayet, 2020b

Random effects mode

Heterogeneity: $I^{2}=99 \%, \tau^{2}=1.6076, p=0$

OD Reported: Smell Test

Hornuss, 2020

Lechien, 2020d

Moein, 2020

Petrocelli, 2020

Vaira, 2020a

Vaira, 2020b

Random effects mode

Heterogeneity: $I^{2}=98 \%, \tau^{2}=1.8630, p<0.01$

Random effects model

Heterogeneity: $I^{2}=99 \%, \tau^{2}=1.7105, p=0$

Residual heterogeneity: $I^{2}=98 \%, p=0$
Prevalence $\quad 95 \%-\mathrm{Cl}$

\section{ction To}

$\begin{array}{rr}50 & 81 \\ 118 & 179\end{array}$

$\begin{array}{rr:r} & & \\ 25 & 79 & 0.66[0.58 ; 0.73]\end{array}$

$0.32[0.22 ; 0.43]$

$0.67[0.58 ; 0.75]$

$0.52[0.33 ; 0.70]$

$0.51[0.43 ; 0.60]$

$0.92[0.86 ; 0.96]$

$0.82[0.78 ; 0.85]$

$0.23[0.10 ; 0.41]$

$0.67[0.41 ; 0.87]$

$0.43[0.28 ; 0.59]$

$0.67[0.62 ; 0.72]$

$0.21[0.18 ; 0.24]$
$0.92[0.81 ; 0.98]$

$0.24[0.14 ; 0.37]$

$0.98[0.97 ; 0.99]$

$0.38[0.32 ; 0.46]$

$0.65[0.46 ; 0.80]$

$0.54[0.50 ; 0.57]$

$0.24[0.16 ; 0.34]$

$0.08[0.05 ; 0.12]$

$0.32[0.26 ; 0.39]$

$0.47[0.38 ; 0.57]$

$0.87[0.86 ; 0.89]$

$0.41[0.28 ; 0.55]$

$0.12[0.11 ; 0.13]$

$0.36[0.22 ; 0.52]$

$0.40[0.29 ; 0.51]$

$0.39[0.29 ; 0.49]$

$0.74[0.62 ; 0.83]$

$0.43[0.32 ; 0.54]$

$0.64[0.57 ; 0.71]$

$0.29[0.20 ; 0.39]$

$0.42[0.35 ; 0.49]$

$0.17[0.09 ; 0.28]$

$0.26[0.20 ; 0.33]$

$0.94[0.83 ; 0.99]$

$0.56[0.51 ; 0.60]$

$0.57[0.48 ; 0.65]$

$0.39[0.34 ; 0.44]$

$0.99[0.94 ; 1.00]$

$0.81[0.70 ; 0.90]$

$0.49[0.47 ; 0.51]$

$0.61[0.51 ; 0.71]$

$0.64[0.57 ; 0.71]$

$0.47[0.36 ; 0.58]$

$0.41[0.34 ; 0.49]$

$0.68[0.62 ; 0.74]$

$0.23[0.16 ; 0.30]$

$0.15[0.08 ; 0.23]$

$0.59[0.50 ; 0.67]$

$0.53[0.41 ; 0.65$

$0.63[0.53 ; 0.73]$

$0.53[0.45 ; 0.62]$

$0.84[0.71 ; 0.94$

$0.62[0.51 ; 0.72]$

$0.98[0.91 ; 1.00]$

$0.63[0.58 ; 0.69]$

$0.83[0.73 ; 0.91]$

$0.30[0.25 ; 0.35]$

$0.76[0.51 ; 0.91]$

$0.56[0.47 ; 0.64]$ deciding the disposition of patients i.e. admission vs outpatient care. However, Moein et al. [19॰] reported that there was no statistically significant difference in the mean UPSIT score between patients with mild, moderate or severe COVID-19. As such, this may be purely be due to recall bias, where patients with severe COVID-19 may be less cognizant of OD due to the presence of more bothersome symptoms such as dyspnoea. The prognostic value of OD in COVID-19 patients remains to be elucidated but is unlikely to override traditional, objective and actionable clinical measurements such as oxygen saturation, pulse rate and respiratory rate.

Various Otolaryngologic societies have issued statements addressing OD in COVID-19. On 21 March 2020, a press release was issued by ENT UK and the British Rhinological Society on Twitter, recommending that anosmia be added to the current symptom criteria used to trigger quarantine and that individuals with new-onset 
Fig. 5 Funnel plots for a metaanalysis A showing the clinical significance OD in the diagnosis of COVID-19 and $\mathbf{b}$ metaanalysis B estimating the frequency of OD amongst COVID19 patients

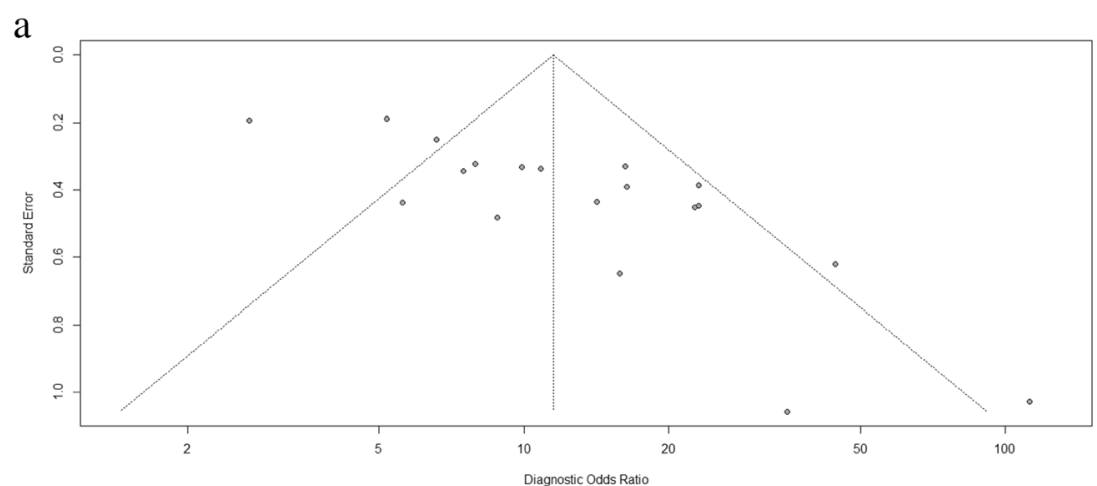

b

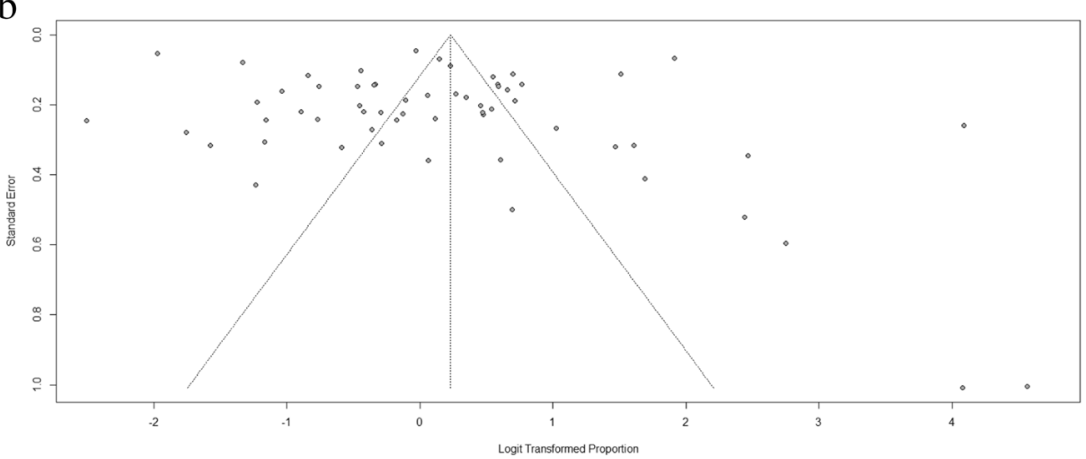

anosmia should self-isolate to reduce the risk of further transmission of COVID-19 [5]. This was largely based on anecdotal physician and media reports [98]. A similar statement was released by the American Academy of Otolaryngology-Head and Neck Surgery (AAO-HNS) on 22 March 2020 [99], and a joint statement was released by the Chapter of Otorhinolaryngologists, College of Surgeons, Singapore, and the Society of OtolaryngologyHead and Neck Surgery, Singapore, on 17 April 2020 [100]. The US Centers for Disease Control and Prevention added "new loss of taste or smell" to the list of COVID-19 symptoms on 17 April 2020, while the World Health Organisation (WHO) has added the above as of 9 May 2020 [101], albeit as a "less common symptom".

The major limitation of the meta-analysis was the significant heterogeneity amongst included studies. Sources of heterogeneity include different inclusion criteria across studies (e.g. only hospitalised patients or only outpatients included, only mild-moderate illness included), different ways in which the OD questions were phrased and possibly the different RT-PCR sensitivities across different institutions around the world for detection of SARS-CoV-2 RNA. We were unable to perform a meta-analysis of the onset, duration and severity of OD due to the varied data collection protocols. As questionnaires were used in most of the studies, there might have been a strong recall bias in which patients who knew they were COVID-19 positive were more likely to report anosmia. Furthermore, it is impossible to survey intubated or deceased patients so findings may not be generalisable to the most severe of patients. Nevertheless, the clinical utility of patientreported OD in identifying COVID-19 infection amongst patients with mild-moderate symptoms remains important to facilitate cohorting and isolation, to minimise transmission.

Future research should utilise validated instruments for both survey/questionnaire (i.e. visual analogue scale [VAS]) and smell testing of OD across various time points to quantify the onset and severity of OD and track its recovery. However, we recognise the inherent difficulties in conducting these tests amongst COVID-19 positive patients as it puts researchers at risk of infection. While it is important to correctly diagnose and classify the severity OD in order to study of the characteristics of hyposmia/ microsmia or anosmia amongst COVID-19 positive, from a public health perspective, it can be argued that the detection of self-reported OD via surveys of questionnaires is equally important in curbing the COVID-19 pandemic by assisting in identifying COVID-19 positive patients.

\section{Conclusion}

Patient-reported OD is a highly specific symptom of COVID19 which should be included as part of the pre-test screening of suspect patients. 


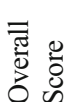

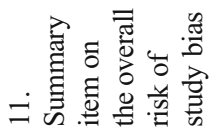

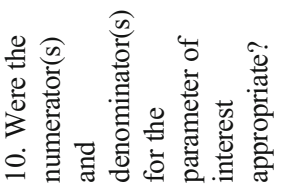

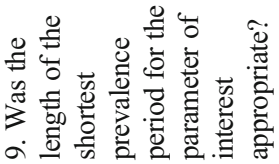

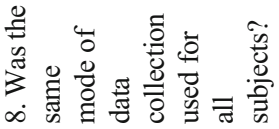

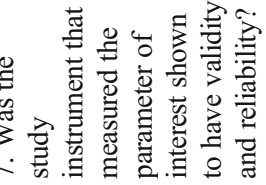

สี 응

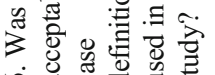

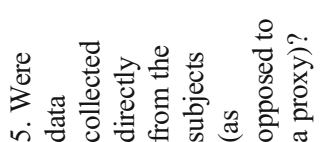

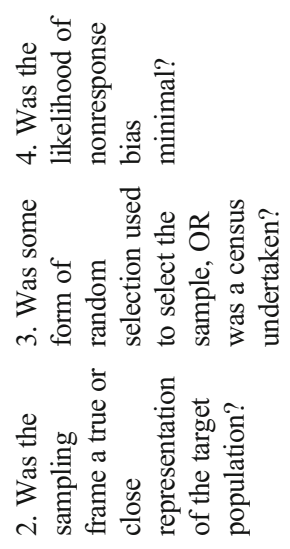

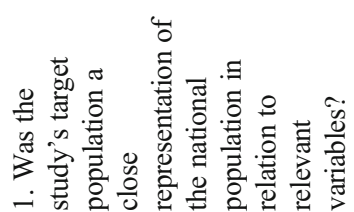

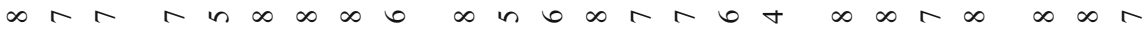

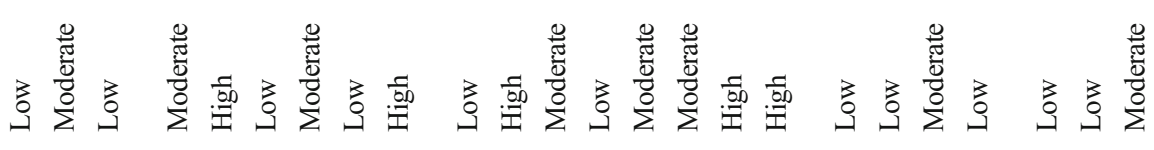
$--$ $--$ $0000000-$ 00000000 $00-0000$

$0-000000000000000000-000$

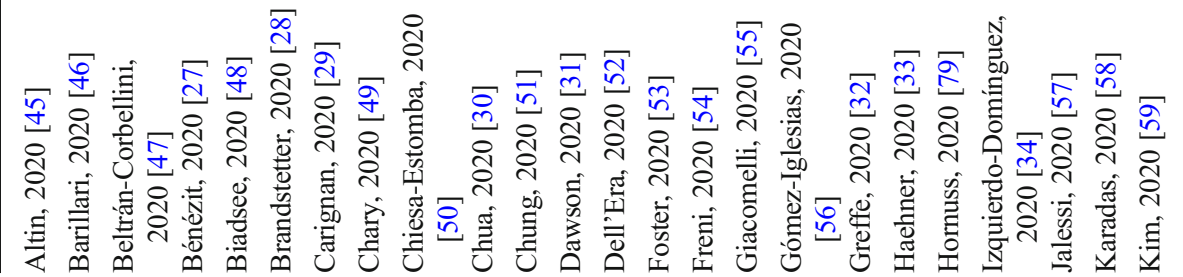


范

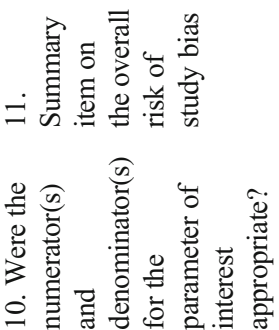

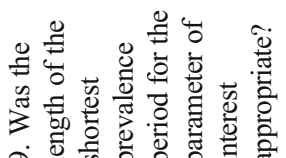

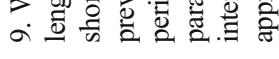

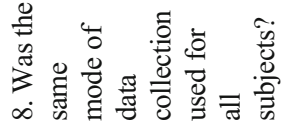

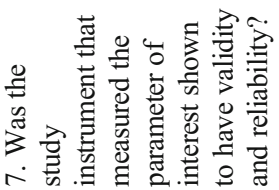

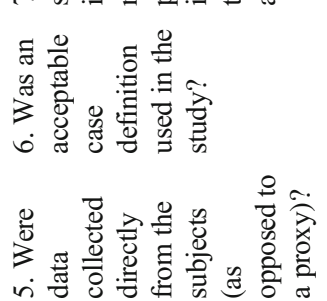

$0-0000000000-0-0000-1-00001$

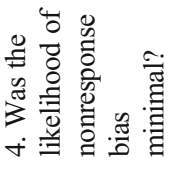

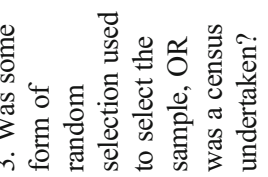

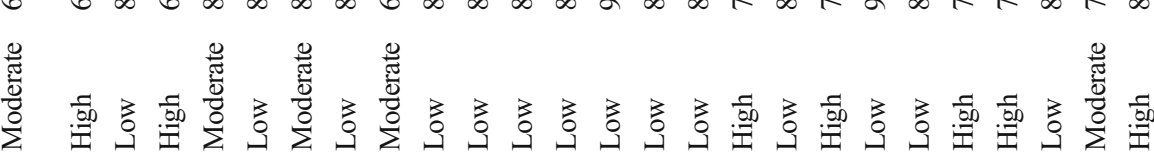
$-\neg-\neg-\neg-\neg-\neg-\neg-\neg-\neg-\neg--\neg-\neg--$ $-$ $-$ 


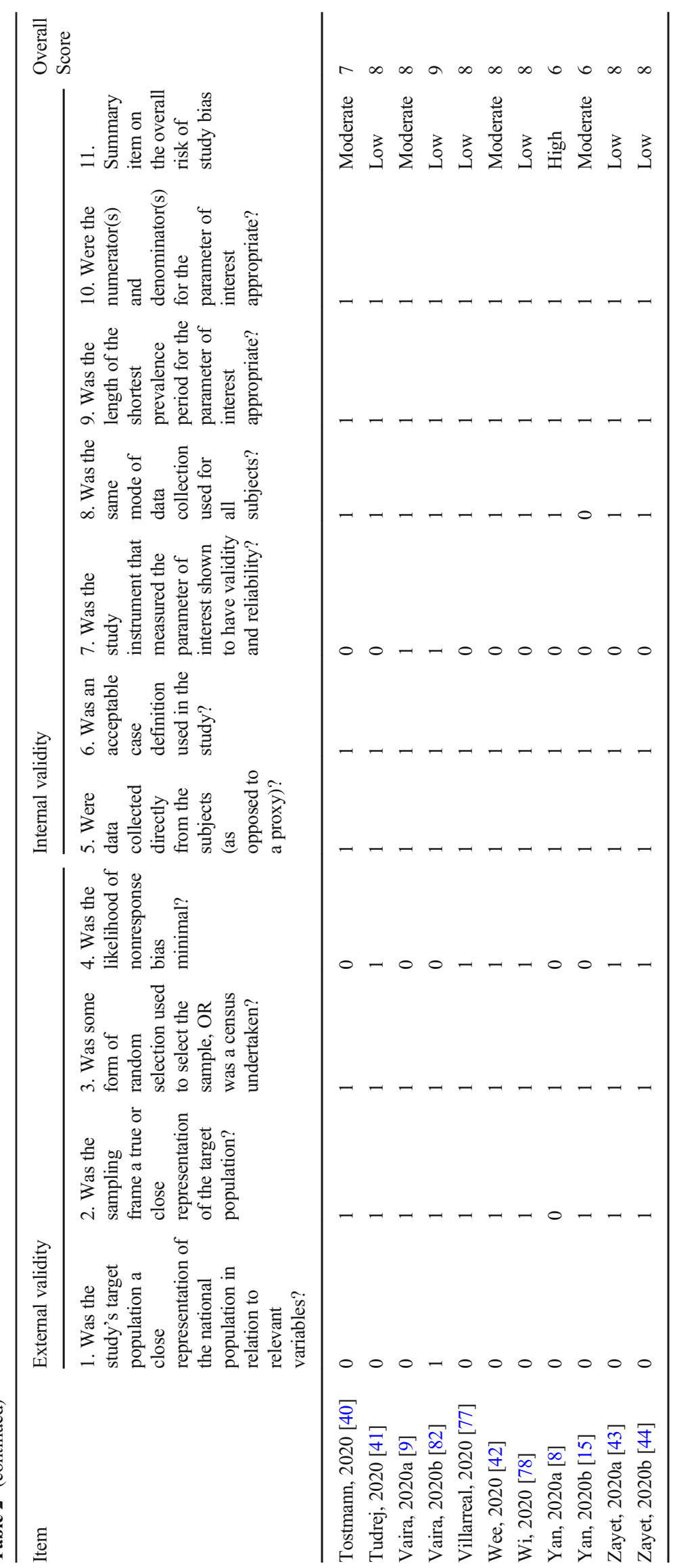


Authors' Contributions Khang Wen Pang and Jeremy Chee contributed equally to this paper and are co-first authors. Somasundaram Subramaniam and Chew Lip $\mathrm{Ng}$ contributed equally to this paper and are co-last authors. Chew Lip Ng and Somasundaram Subramaniam conceptualised the study. Khang Wen Pang and Jeremy Chee designed the study. Khang Wen Pang and Jeremy Chee screened titles and abstracts for inclusion. Khang Wen Pang and Jeremy Chee extracted and analysed data. Khang Wen Pang, Jeremy Chee, Chew Lip Ng and Somasundaram Subramaniam helped interpret the findings from the meta-analyses and interpretation from a clinical viewpoint. Khang Wen Pang and Jeremy Chee wrote the first draft, which all authors revised for critical content. All authors approved the final manuscript. Khang Wen Pang and Jeremy Chee are the guarantors. The corresponding author attests that all listed authors meet authorship criteria and that no others meeting the criteria have been omitted.

Data Availability The authors will share data upon reasonable request.

\section{Compliance with Ethical Standards}

Conflict of Interest The authors declare no conflicts of interest relevant to this manuscript.

Human and Animal Rights and Informed Consent This article does not contain any studies with human or animal subjects performed by any of the authors.

Ethics Approval Not required for this study.

Consent to Participate Not applicable.

Consent for Publication Not applicable.

Code Availability The authors will share the full statistical code upon reasonable request.

\section{References}

Papers of particular interest, published recently, have been highlighted as:

- Of importance

•- Of major importance

1. Izquierdo-Dominguez A, Rojas-Lechuga MJ, Mullol J, Alobid I. Olfactory dysfunction in the COVID-19 outbreak. J Investig Allergol Clin Immunol. 2020:0. https://doi.org/10.18176/jiaci. 0567.

2. Mullol J, Alobid I, Mariño-Sánchez F, Izquierdo-Domínguez A, Marin C, Klimek L, et al. The loss of smell and taste in the COVID-19 outbreak - a tale of many countries. Curr Allergy Asthma Rep. 2020;20:61.

3. Boesveldt S, Postma EM, Boak D, Welge-Luessen A, Schopf V, Mainland JD, et al. Anosmia-a clinical review. Chem Senses. 2017;42(7):513-23. https://doi.org/10.1093/chemse/bjx025.

4. Mullol J, Alobid I, Mariño-Sánchez F, Quintó L, de Haro J, Bernal-Sprekelsen M, et al. Furthering the understanding of olfaction, prevalence of loss of smell and risk factors: a populationbased survey (OLFACAT study). BMJ Open. 2012;2(6):e001256. https://doi.org/10.1136/bmjopen-2012-001256.
5. ENT-UK. Loss of sense of smell as marker of COVID-19 infection. 2020. https://www.entuk.org/sites/default/files/files/Loss-ofsense-of-smell-0as-marker-of-COVID.pdf. Accessed 9 May 2020.

6. Jaume F, Quintó L, Alobid I, Mullol J. Overuse of diagnostic tools and medications in acute rhinosinusitis in Spain: a populationbased study (the PROSINUS study). BMJ Open. 2018;8(1): e018788. https://doi.org/10.1136/bmjopen-2017-018788.

7. Lechien JR, Chiesa-Estomba CM, De Siati DR, Horoi M, Le Bon $\mathrm{SD}$, Rodriguez A, et al. Olfactory and gustatory dysfunctions as a clinical presentation of mild-to-moderate forms of the coronavirus disease (COVID-19): a multicenter European study. Eur Arch Otorhinolaryngol. 2020;277:2251-61. https://doi.org/10.1007/ s00405-020-05965-1.

8. Yan CH, Faraji F, Prajapati DP, Boone CE, DeConde AS. Association of chemosensory dysfunction and Covid-19 in patients presenting with influenza-like symptoms. Int Forum Allergy Rhinol. 2020;10:806-13. https://doi.org/10.1002/alr. 22579.

9. Vaira LA, Deiana G, Fois AG, Pirina P, Madeddu G, De Vito A, et al. Objective evaluation of anosmia and ageusia in COVID-19 patients: single-center experience on 72 cases. Head Neck. 2020;42:1252-8. https://doi.org/10.1002/hed.26204.

10. Lee Y, Min P, Lee S, Kim SW. Prevalence and duration of acute loss of smell or taste in COVID-19 patients. J Korean Med Sci. 2020;35(18):e174. https://doi.org/10.3346/jkms.2020.35.e174.

11. Desforges M, Le Coupanec A, Dubeau P, Bourgouin A, Lajoie L, Dube $\mathrm{M}$ et al. Human coronaviruses and other respiratory viruses: underestimated opportunistic pathogens of the central nervous system? Viruses. 2019;12(1). https://doi.org/10.3390/v12010014.

12. Mori I. Transolfactory neuroinvasion by viruses threatens the human brain. Acta Virol. 2015;59(4):338-49. https://doi.org/10. 4149/av_2015_04_338.

13.•• Brann D, Tsukahara T, Weinreb C. Non-neuronal expression of SARS-CoV-2 entry genes in the olfactory system suggests mechanisms underlying COVID-19-associated anosmia. Sci Adv. 2020. A summary of the mechanisms of action of olfactory dysfunction in COVID-19.

14. Bilinska K, Jakubowska P, Von Bartheld CS, Butowt R. Expression of the SARS-CoV-2 entry proteins, ACE2 and TMPRSS2, in cells of the olfactory epithelium: identification of cell types and trends with age. ACS Chem Neurosci. 2020;11(11): 1555-62. https://doi.org/10.1021/acschemneuro.0c00210.

15. Yan CH, Faraji F, Prajapati DP, Ostrander BT, DeConde AS. Selfreported olfactory loss associates with outpatient clinical course in Covid-19. Int Forum Allergy Rhinol. 2020;10:821-31. https://doi. org/10.1002/alr.22592.

16. Menni C, Valdes AM, Freidin MB, Sudre CH, Nguyen LH, Drew DA, et al. Real-time tracking of self-reported symptoms to predict potential COVID-19. Nat Med. 2020;26(7):1037-40. https://doi. org/10.1038/s41591-020-0916-2.

17. Wehling E, Nordin S, Espeseth T, Reinvang I, Lundervold AJ. Unawareness of olfactory dysfunction and its association with cognitive functioning in middle aged and old adults. Arch Clin Neuropsychol. 2011;26(3):260-9. https://doi.org/10.1093/arclin/ acr019.

18. Adams DR, Wroblewski KE, Kern DW, Kozloski MJ, Dale W, McClintock MK, et al. Factors associated with inaccurate selfreporting of olfactory dysfunction in older US adults. Chem Senses. 2017;42(3):223-31. https://doi.org/10.1093/chemse/ bjw108.

19. Moein ST, Hashemian SMR, Mansourafshar B, Khorram-Tousi A, Tabarsi P, Doty RL. Smell dysfunction: a biomarker for COVID-19. Int Forum Allergy Rhinol. 2020;n/a(n/a). https://doi. org/10.1002/alr.22587. This study demonstrates high incidence of olfactory dysfunction amongst patients with COVID-19. It 
also demonstrates the disparity between subjective and objective olfactory dysfunction. However, the reliability of the used smell test (UPSIT) was low since it was not validated in Iranian population (see [27]).

20. Moher D, Liberati A, Tetzlaff J, Altman DG, Group P. Preferred reporting items for systematic reviews and meta-analyses: the PRISMA statement. PLoS Med. 2009;6(7):e1000097-e. https:// doi.org/10.1371/journal.pmed.1000097.

21. Hoy D, Brooks P, Woolf A, Blyth F, March L, Bain C, et al. Assessing risk of bias in prevalence studies: modification of an existing tool and evidence of interrater agreement. J Clin Epidemiol. 2012;65(9):934-9. https://doi.org/10.1016/j.jclinepi. 2011.11.014.

22. RStudio Team. RStudio: integrated development for R. Boston: RStudio, Inc.; 2020.

23. R Core Team. R: a language and environment for statistical computing. Vienna: R Foundation for Statistical Computing; 2020.

24. Balduzzi S, Rucker G, Schwarzer G. How to perform a metaanalysis with R: a practical tutorial. Evid Based Ment Health. 2019;22(4):153-60. https://doi.org/10.1136/ebmental-2019300117.

25. Doebler P. mada: meta-analysis of diagnostic accuracy. R package version 0.5.10. 2020. https://CRAN.R-project.org/package=mada.

26. Harrer M, Cuijpers P, Furukawa T, Ebert DD. dmetar: companion $\mathrm{R}$ package for the guide 'doing meta-analysis in $\mathrm{R}$ '. $\mathrm{R}$ package version 0.0.9000. 2019. http://dmetar.protectlab.org.

27. Bénézit F, Le Turnier P, Declerck C, Paillé C, Revest M, Dubée V, et al. Utility of hyposmia and hypogeusia for the diagnosis of COVID-19. Lancet Infect Dis. 2020. https://doi.org/10.1016/ S1473-3099(20)30297-8.

28. Brandstetter S, Roth S, Harner S, Buntrock-Döpke H, Toncheva AA, Borchers N et al. Symptoms and immunoglobulin development in hospital staff exposed to a SARS-CoV-2 outbreak. Pediatr Allergy Immunol. 2020;n/a(n/a). https://doi.org/10.1111/pai. 13278.

29. Carignan A, Valiquette L, Grenier C, Musonera JB, Nkengurutse D, Marcil-Héguy A, et al. Anosmia and dysgeusia associated with SARS-CoV-2 infection: an age-matched case-control study. CMAJ. 2020;192(26):E702. https://doi.org/10.1503/cmaj. 200869.

30. Kai Chua AJ, Yun Chan EC, Loh J, Charn TC. Acute olfactory loss is specific for Covid-19 at the emergency department. Ann Emerg Med. 2020. https://doi.org/10.1016/j.annemergmed.2020. 05.015 .

31. Dawson P, Rabold EM, Laws RL, Conners EE, Gharpure R, Yin $\mathrm{S}$, et al. Loss of taste and smell as distinguishing symptoms of coronavirus disease 2019. Clin Infect Dis. 2020. https://doi.org/ $10.1093 / \mathrm{cid} / \mathrm{ciaa} 799$.

32. Greffe S, Espinasse F, Duran C, Labrune S, Sirol M, Mantalvan B, et al. Évaluation par RT-PCR du portage nasopharyngé du SARSCov-2 chez les personnels de santé symptomatiques suspects de COVID-19 dans un CHU de la banlieue parisienne. Rev Med Interne. 2020;41:510-6. https://doi.org/10.1016/j.revmed.2020. 06.017.

33. Haehner A, Draf J, Dräger S, de With K, Hummel T. Predictive value of sudden olfactory loss in the diagnosis of COVID- 19 . ORL J Otorhinolaryngol Relat Spec. 2020;82:1-6. https://doi. org/10.1159/000509143.

34. Izquierdo-Domínguez A, Rojas-Lechuga MJ, Chiesa-Estomba C, Calvo-Henríquez C, Ninchritz-Becerra E, Soriano-Reixach M et al. Smell and taste dysfunctions in COVID-19 are associated with younger age in ambulatory settings - a multicenter crosssectional study. J Investig Allergol Clin Immunol. 2020:0. https://doi.org/10.18176/jiaci.0595.

35. Lee DJ, Lockwood J, Das P, Wang R, Grinspun E, Lee JM. Selfreported anosmia and dysgeusia as key symptoms of coronavirus disease. CJEM. 2019;2020:1-8. https://doi.org/10.1017/cem. 2020.420 .

36. Magnavita N, Tripepi G, Di Prinzio RR. Symptoms in health care workers during the COVID-19 epidemic. A cross-sectional survey. Int J Environ Res Public Health. 2020;17(14):5218.

37. Martin-Sanz E, Riestra J, Yebra L, Larran A, Mancino F, YanesDiaz J et al. Prospective study in 355 patients with suspected COVID-19 infection. Value of cough, subjective hyposmia, and hypogeusia. Laryngoscope.n/a(n/a). https://doi.org/10.1002/lary. 28999.

38. Merkely B, Szabó AJ, Kosztin A, Berényi E, Sebestyén A, Lengyel C, et al. Novel coronavirus epidemic in the Hungarian population, a cross-sectional nationwide survey to support the exit policy in Hungary. GeroScience. 2020;42(4):1063-74. https://doi. org/10.1007/s11357-020-00226-9.

39. Sayin İ, Yaşar KK, Yazici ZM. Taste and smell impairment in COVID-19: an AAO-HNS anosmia reporting tool-based comparative study. Otolaryngol Head Neck Surg. 2020;0194599820931820:473-9. https://doi.org/10.1177/ 0194599820931820 .

40. Tostmann A, Bradley J, Bousema T, Yiek WK, Holwerda M, Bleeker-Rovers $\mathrm{C}$ et al. Strong associations and moderate predictive value of early symptoms for SARS-CoV-2 test positivity among healthcare workers, the Netherlands, March 2020. Euro Surveill. 2020;25(16). https://doi.org/10.2807/1560-7917.Es. 2020.25.16.2000508.

41. Tudrej B, Sebo P, Lourdaux J, Cuzin C, Floquet M, Haller DM, et al. Self-reported loss of smell and taste in SARS-CoV-2 patients: primary care data to guide future early detection strategies. J Gen Intern Med. 2020;35:1-3. https://doi.org/10.1007/s11606020-05933-9.

42. Wee LE, Chan YFZ, Teo NWY, Cherng BPZ, Thien SY, Wong HM, et al. The role of self-reported olfactory and gustatory dysfunction as a screening criterion for suspected COVID-19. Eur Arch Otorhinolaryngol. 2020;277:2389-90. https://doi.org/10. 1007/s00405-020-05999-5.

43. Zayet S, Kadiane-Oussou NdJ, Lepiller Q, Zahra H, Royer P-Y, Toko L et al. Clinical features of COVID-19 and influenza: a comparative study on Nord Franche-Comte cluster. Microbes Infect. 2020:S1286-4579(20)30094-0. https://doi.org/10.1016/j. micinf.2020.05.016.

44. Zayet S, Klopfenstein T, Mercier J, Kadiane-Oussou NJ, Lan Cheong Wah L, Royer PY, et al. Contribution of anosmia and dysgeusia for diagnostic of COVID-19 in outpatients. Infection. 2020:1-5. https://doi.org/10.1007/s15010-020-01442-3.

45. Altin F, Cingi C, Uzun T, Bal C. Olfactory and gustatory abnormalities in COVID-19 cases. Eur Arch Otorhinolaryngol. 2020;277:1-7. https://doi.org/10.1007/s00405-020-06155-9.

46. Barillari MR, Bastiani L, Lechien JR, Mannelli G, Molteni G, Cantarella $\mathrm{G}$, et al. A structural equation model to examine the clinical features of mild-to-moderate Covid-19: a multicenter Italian study. J Med Virol. 2020. https://doi.org/10.1002/jmv. 26354.

47. Beltran-Corbellini A, Chico-Garcia JL, Martinez-Poles J, Rodriguez-Jorge F, Natera-Villalba E, Gomez-Corral J, et al. Acute-onset smell and taste disorders in the context of Covid19: a pilot multicenter PCR-based case-control study. Eur J Neurol. 2020;27:1738-41. https://doi.org/10.1111/ene.14273.

48. Biadsee A, Biadsee A, Kassem F, Dagan O, Masarwa S, Ormianer Z. Olfactory and oral manifestations of COVID-19: sex-related symptoms - a potential pathway to early diagnosis. Otolaryngol Head Neck Surg. 2020;0194599820934380:019459982093438. https://doi.org/10.1177/0194599820934380.

49. Chary E, Carsuzaa F, Trijolet JP, Capitaine AL, Roncato-Saberan $\mathrm{M}$, Fouet $\mathrm{K}$, et al. Prevalence and recovery from olfactory and gustatory dysfunctions in Covid-19 infection: a prospective 
multicenter study. Am J Rhinol Allergy. 2020;1945892420930954:686-93. https://doi.org/10.1177/ 1945892420930954.

50. Chiesa-Estomba CM, Lechien JR, Portillo-Mazal P, Martínez F, Cuauro-Sanchez J, Calvo-Henriquez C, et al. Olfactory and gustatory dysfunctions in COVID-19. First reports of Latin-American ethnic patients. Am J Otolaryngol. 2020;41(5):102605. https://doi. org/10.1016/j.amjoto.2020.102605.

51. Chung TW-H, Sridhar S, Zhang AJ, Chan K-H, Li H-L, Wong FK-C, et al. Olfactory dysfunction in coronavirus disease 2019 patients: observational cohort study and systematic review. Open Forum Infect Dis. 2020;7(6):ofaa199-ofaa. https://doi.org/10. 1093/ofid/ofaa199.

52. Dell'Era V, Farri F, Garzaro G, Gatto M, Aluffi Valletti P, Garzaro M. Smell and taste disorders during COVID-19 outbreak: a crosssectional study on 355 patients. Head Neck. 2020. https://doi.org/ 10.1002/hed.26288.

53. Foster KJ, Jauregui E, Tajudeen B, Bishehsari F, Mahdavinia M. Smell loss is a prognostic factor for lower severity of COVID-19. Ann Allergy Asthma Immunol. 2020. https://doi.org/10.1016/j. anai.2020.07.023.

54. Freni F, Meduri A, Gazia F, Nicastro V, Galletti C, Aragona P, et al. Symptomatology in head and neck district in coronavirus disease (COVID-19): a possible neuroinvasive action of SARSCoV-2. Am J Otolaryngol. 2020;41(5):102612. https://doi.org/10. 1016/j.amjoto.2020.102612.

55. Giacomelli A, Pezzati L, Conti F, Bernacchia D, Siano M, Oreni $\mathrm{L}$, et al. Self-reported olfactory and taste disorders in patients With severe acute respiratory coronavirus 2 infection: a cross-sectional study. Clin Infect Dis. 2020;71:889-90. https://doi.org/10.1093/ $\mathrm{cid} / \mathrm{ciaa330.}$

56. Gómez-Iglesias P, Porta-Etessam J, Montalvo T, Valls-Carbó A, Gajate V, Matías-Guiu JA, et al. An online observational study of patients with olfactory and gustory alterations secondary to SARS-CoV-2 infection. Front Public Health. 2020;8:243. https:// doi.org/10.3389/fpubh.2020.00243.

57. Jalessi M, Barati M, Rohani M, Amini E, Ourang A, Azad Z, et al. Frequency and outcome of olfactory impairment and sinonasal involvement in hospitalized patients with COVID-19. Neurol Sci. 2020;41:2331-8. https://doi.org/10.1007/s10072-02004590-4.

58. Karadaș Ö, Öztürk B, Sonkaya AR. A prospective clinical study of detailed neurological manifestations in patients with COVID19. Neurol Sci. 2020. https://doi.org/10.1007/s10072-020-045477.

59. Kim GU, Kim MJ, Ra SH, Lee J, Bae S, Jung J, et al. Clinical characteristics of asymptomatic and symptomatic patients with mild COVID-19. Clin Microbiol Infect. 2020;26:948.e1-3. https://doi.org/10.1016/j.cmi.2020.04.040.

60. Klopfenstein T, Kadiane-Oussou NJ, Toko L, Royer PY, Lepiller Q, Gendrin V et al. Features of anosmia in COVID-19. Med Mal Infect. 2020:S0399-077X(20)30110-4. https://doi.org/10.1016/j. medmal.2020.04.006.

61. Lechien JR, Chiesa-Estomba CM, Hans S, Barillari MR, Jouffe L, Saussez S. Loss of smell and taste in 2013 European patients with mild to moderate COVID-19. Ann Intern Med. 2020. https://doi. org/10.7326/M20-2428.

62. Levinson R, Elbaz M, Ben-Ami R, Shasha D, Levinson T, Choshen $\mathrm{G}$, et al. Time course of anosmia and dysgeusia in patients with mild SARS-CoV-2 infection. Infect Dis (Lond). 2020;52(8):600-2. https://doi.org/10.1080/23744235.2020. 1772992

63. Liang Y, Xu J, Chu M, Mai J, Lai N, Tang W, et al. Neurosensory dysfunction: a diagnostic marker of early COVID-19. Int J Infect Dis. 2020;98:347-52. https://doi.org/10.1016/j.ijid.2020.06.086.
64. Liguori C, Pierantozzi M, Spanetta M, Sarmati L, Cesta N, Iannetta $\mathrm{M}$, et al. Subjective neurological symptoms frequently occur in patients with SARS-CoV2 infection. Brain Behav Immun. 2020;88:11-6. https://doi.org/10.1016/j.bbi.2020.05.037.

65. Luers JC, Rokohl AC, Loreck N, Wawer Matos PA, Augustin M, Dewald F, et al. Olfactory and gustatory dysfunction in coronavirus disease 19 (COVID-19). Clin Infect Dis. 2020. https://doi.org/ $10.1093 / \mathrm{cid} / \mathrm{ciaa} 525$.

66. Meini S, Suardi LR, Busoni M, Roberts AT, Fortini A. Olfactory and gustatory dysfunctions in 100 patients hospitalized for COVID-19: sex differences and recovery time in real-life. Eur Arch Otorhinolaryngol. 2020:1-5. https://doi.org/10.1007/ s00405-020-06102-8.

67. Mercante G, Ferreli F, De Virgilio A, Gaino F, Di Bari M, Colombo G, et al. Prevalence of taste and smell dysfunction in coronavirus disease 2019. JAMA Otolaryngol Head Neck Surg. 2020;146:723. https://doi.org/10.1001/jamaoto.2020.1155.

68. Noh JY, Yoon JG, Seong H, Choi WS, Sohn JW, Cheong HJ et al. Asymptomatic infection and atypical manifestations of COVID19: comparison of viral shedding duration. J Infect. 2020:S01634453(20)30310-8. https://doi.org/10.1016/j.jinf.2020.05.035.

69. Otte MS, Klussmann JP, Luers JC. Persisting olfactory dysfunction in patients after recovering from COVID-19. J Inf Secur. 2020;81:e58. https://doi.org/10.1016/j.jinf.2020.06.054.

70. Paderno A, Schreiber A, Grammatica A, Raffetti E, Tomasoni M, Gualtieri T, et al. Smell and taste alterations in COVID-19: a cross-sectional analysis of different cohorts. Int Forum Allergy Rhinol. 2020;10(8):955-62. https://doi.org/10.1002/alr.22610.

71. Patel A, Charani E, Ariyanayagam D, Abdulaal A, Denny SJ, Mughal N, et al. New-onset anosmia and ageusia in adult patients diagnosed with SARS-CoV-2 infection. Clin Microbiol Infect. 2020;26:1236-41. https://doi.org/10.1016/j.cmi.2020.05.026.

72. Qiu C, Cui C, Hautefort C, Haehner A, Zhao J, Yao Q et al. Olfactory and gustatory dysfunction as an early identifier of COVID-19 in adults and children: An International Multicenter Study. Otolaryngol Head Neck Surg. 2020:194599820934376https://doi.org/10.1177/0194599820934376.

73. Renaud M, Leon A, Trau G, Fath L, Ciftci S, Bensimon Y, et al. Acute smell and taste loss in outpatients: all infected with SARSCoV-2? Rhinology. 2020;0:0. https://doi.org/10.4193/Rhin20. 199.

74. Sierpiński R, Pinkas J, Jankowski M, Zgliczyński WS, Wierzba W, Gujski M, et al. Sex differences in the frequency of gastrointestinal symptoms and olfactory or taste disorders in 1942 nonhospitalized patients with coronavirus disease 2019 (COVID-19). Pol Arch Intern Med. 2020;130(6):501-5. https://doi.org/10.20452/ pamw.15414.

75. Speth MM, Singer-Cornelius T, Obere M, Gengler I, Brockmeier SJ, Sedaghat AR. Olfactory dysfunction and sinonasal symptomatology in COVID-19: prevalence, severity, timing, and associated characteristics. Otolaryngol Head Neck Surg. 2020;0194599820929185:114-20. https://doi.org/10.1177/ 0194599820929185.

76. Spinato G, Fabbris C, Polesel J, Cazzador D, Borsetto D, Hopkins $\mathrm{C}$, et al. Alterations in smell or taste in mildly symptomatic outpatients with SARS-CoV-2 infection. JAMA. 2020;323(20): 2089-90. https://doi.org/10.1001/jama.2020.6771.

77. Villarreal IM, Morato M, Martínez-RuizCoello M, Navarro A, Garcia-Chillerón R, Ruiz Á, et al. Olfactory and taste disorders in healthcare workers with COVID-19 infection. Eur Arch Otorhinolaryngol. 2020:1-5. https://doi.org/10.1007/s00405020-06237-8.

78. Wi YM, Lim SJ, Kim S-H, Lim S, Lee SJ, Ryu B-H, et al. Response system for and epidemiological features of COVID-19 in Gyeongsangnam-do Province in South Korea. Clin Infect Dis. 2020. https://doi.org/10.1093/cid/ciaa967. 
79. Hornuss D, Lange B, Schröter N, Rieg S, Kern WV, Wagner D. Anosmia in COVID-19 patients. Clin Microbiol Infect. 2020: S1198-743X(20)30294-9. https://doi.org/10.1016/j.cmi.2020.05. 017.

80. Lechien JR, Cabaraux P, Chiesa-Estomba CM, Khalife M, Hans $\mathrm{S}$, Calvo-Henriquez C, et al. Objective olfactory evaluation of selfreported loss of smell in a case series of 86 COVID-19 patients. Head Neck. 2020;42(7):1583-90. https://doi.org/10.1002/hed. 26279.

81. Petrocelli M, Ruggiero F, Baietti AM, Pandolfi P, Salzano G, Salzano FA, Lechien JR, Saussez S, de Riu G, Vaira LA Remote psychophysical evaluation of olfactory and gustatory functions in early-stage coronavirus disease 2019 patients: the Bologna experience of 300 cases. J Laryngol Otol 2020:1-6. https://doi.org/10.1017/S0022215120001358.

82. Vaira LA, Hopkins C, Salzano G, Petrocelli M, Melis A, Cucurullo $\mathrm{M}$, et al. Olfactory and gustatory function impairment in COVID-19 patients: Italian objective multicenter-study. Head Neck. 2020;42(7):1560-9. https://doi.org/10.1002/hed.26269.

83. Abalo-Lojo JM, Pouso-Diz JM, Gonzalez F. Taste and smell dysfunction in COVID-19 patients. Ann Otol Rhinol Laryngol. 2020;0003489420932617:1041-2. https://doi.org/10.1177/ 0003489420932617.

84. Adorni F, Prinelli F, Bianchi F, Giacomelli A, Pagani G, Bernacchia D, et al. Self-reported symptoms of SARS-CoV-2 infection in a non-hospitalized population: results from the large Italian web-based EPICOVID19 cross-sectional survey. JMIR Public Health Surveill. 2020;6:e21866. https://doi.org/10.2196/ 21866.

85. Aggarwal S, Garcia-Telles N, Aggarwal G, Lavie C, Lippi G, Henry BM. Clinical features, laboratory characteristics, and outcomes of patients hospitalized with coronavirus disease 2019 (COVID-19): early report from the United States. Diagnosis (Berl). 2020;7(2):91-6. https://doi.org/10.1515/dx-2020-0046.

86. Gelardi M, Trecca E, Cassano M, Ciprandi G. Smell and taste dysfunction during the COVID-19 outbreak: a preliminary report. Acta Biomed. 2020;91(2):230-1. https://doi.org/10.23750/abm. v91i2.9524.

87. Lechien JR, Chiesa-Estomba CM, Cabaraux P, Mat Q, Huet K, Harmegnies B, et al. Features of mild-to-moderate COVID-19 patients with dysphonia. J Voice. 2020. https://doi.org/10.1016/j. jvoice.2020.05.012.

88. Lechien JR, Chiesa-Estomba CM, Place S, Van Laethem Y, Cabaraux P, Mat Q, et al. Clinical and epidemiological characteristics of 1,420 European patients with mild-to-moderate coronavirus disease 2019. J Intern Med. 2020;288:335-44. https://doi. org/10.1111/joim.13089.

89. Lehrich BM, Goshtasbi K, Raad RA, Ganti A, Papagiannopoulos $\mathrm{P}$, Tajudeen BA, et al. Aggregate prevalence of chemosensory and sinonasal dysfunction in SARS-CoV-2 and related coronaviruses. Otolaryngol Head Neck Surg. 2020;163(1):156-61. https://doi. org/10.1177/0194599820929278.

90. Mao L, Jin $\mathrm{H}$, Wang M, Hu Y, Chen S, He Q, et al. Neurologic manifestations of hospitalized patients With coronavirus disease 2019 in Wuhan, China. JAMA Neurol. 2020;77:683-90. https:// doi.org/10.1001/jamaneurol.2020.1127.
91.• Paderno A, Mattavelli D, Rampinelli V, Grammatica A, Raffetti $\mathrm{E}$, Tomasoni $\mathrm{M}$ et al. Olfactory and gustatory outcomes in COVID-19: a prospective evaluation in nonhospitalized subjects. Otolaryngol Head Neck Surg. 2020:194599820939538-. https:// doi.org/10.1177/0194599820939538. An excellent study which investigates the course of olfactory dysfunction in prospective cohort, as well as the natural history of symptoms.

92. Peyrony O, Marbeuf-Gueye C, Truong V, Giroud M, Rivière C, Khenissi K et al. Accuracy of emergency department clinical findings for diagnosis of coronavirus disease 2019. Ann Emerg Med. 2020:S0196-644(20)30393-0. https://doi.org/10.1016/j. annemergmed.2020.05.022

93. Romero-Sánchez CM, Díaz-Maroto I, Fernández-Díaz E, Sánchez-Larsen Á, Layos-Romero A, García-García J, et al. Neurologic manifestations in hospitalized patients with COVID19: the ALBACOVID registry. Neurology. 2020;95:e1060-70. https://doi.org/10.1212/wnl.0000000000009937.

94. Trigo J, García-Azorín D, Planchuelo-Gómez Á, Martínez-Pías E, Talavera B, Hernández-Pérez I, et al. Factors associated with the presence of headache in hospitalized COVID-19 patients and impact on prognosis: a retrospective cohort study. J Headache Pain. 2020;21(1):94. https://doi.org/10.1186/s10194-020-01165-8.

95. Trubiano JA, Vogrin S, Kwong JC, Homes N. Alterations in smell or taste - classic coronavirus disease 2019? Clin Infect Dis. 2020. https://doi.org/10.1093/cid/ciaa655.

96. Marino-Sanchez F, Santamaria-Gadea A, de Los SG, Alobid I, Mullol J. Psychophysical olfactory testing in COVID-19: is smell function really impaired in nearly all patients? Int Forum Allergy Rhinol. 2020;10:951-2. https://doi.org/10.1002/alr.22639.

97. Chee J, Loh W, Liu Z, Mullol J, Wang D. Clinical-pathological correlation of the pathophysiology and mechanism of action of COVID-19 - a primer for clinicians. Curr Allergy Asthma Rep. 2020(2020 Oct [In press]).

98. O'Donovan J, Tanveer S, Jones N, Hopkins C, Senior BA, Wise SK et al. Sniffing out the evidence for olfactory symptoms as a clinical feature of COVID-19: a systematic scoping review. Centre for Evidence-Based Medicine 2020. https://www.cebm.net/wpcontent/uploads/2020/03/Rapid-Review-Anosmia-COVID19-. pdf. Accessed 9 May 2020.

99. American Academy of Otolaryngology-Head and Neck Surgery. AAO-HNS: anosmia, hyposmia, and dysgeusia symptoms of coronavirus disease. 2020. https://www.entnet.org/content/aao-hnsanosmia-hyposmia-and-dysgeusia-symptoms-coronavirusdisease. Accessed 9 May 2020.

100. Joint statement of the Chapter of Otorhinolaryngologists College of Surgeons Singapore and the Society of Otolaryngology-Head and Neck Surgery Singapore. Acute olfactory and gustatory dysfunction as a symptom of COVID-19 infection. 2020. https:// www.sohnss.org/uploads/8/7/2/4/87246396/07. chapter and society_statement_on_anosmia_nt-2.pdf. Accessed 9 May 2020 .

101. World Health Organisation. Coronavirus - symptoms. 2020. https://www.who.int/health-topics/coronavirus\#tab=tab 3 . Accessed 9 May 2020.

Publisher's Note Springer Nature remains neutral with regard to jurisdictional claims in published maps and institutional affiliations. 